\title{
La legitimidad de la reforma fiscal: autoridades tributarias y contribuyentes en el mercado de la ciudad de Veracruz, 1875-1889
}

\section{The Legitimacy of Tax Reform: Tax Authorities and Tax Payers in the Veracruz City Market, 1875-1889}

\author{
Dora Sánchez Hidalgo Hernández \\ Instituto de Investigaciones Histórico Sociales-Universidad Veracruzana, \\ México | dsanchezhidalgo@uv.mx
}

\begin{abstract}
Resumen
Uno de los retos más difíciles para instrumentar la reforma fiscal del siglo xix en México fue transitar del cobro de los derechos municipales (de mercado y consumo) a los de patente. Las tensiones entre la ley y la realidad generadas por esta transformación tributaria parecían haber convencido a los defensores más aguerridos de la reforma de su inviabilidad. El caso de la ciudad de Veracruz ayuda a explicar cómo fue gracias a las tensiones entre la ley y la praxis cotidiana que los regidores del Ayuntamiento consiguieron regular la recaudación en los mercados urbanos, con base en los derechos de patente. Los procesos de negociación entre autoridades tributarias, contribuyentes y el gobierno estatal permitieron crear los mecanismos tributarios basados en el "giro", con los que se legitimó la reforma fiscal federal desde el ámbito local.
\end{abstract}

Palabras clave: reforma fiscal; derechos de mercado; consumo y giro; autoridades tributarias; contribuyentes; mercados urbanos.

\begin{abstract}
One of the main challenges for the nineteenth century Fiscal Reform in Mexico was the transition from municipal duties (market and consumption) to patente. The tensions between law and reality created by this fiscal transformation appeared to have had convinced the more enthusiastic advocates of the reform of its own infeasibility. Based on the case of Veracruz City, this article explains that it was precisely in the tensions between law and daily praxis where the Ayuntamiento's councilors were able to collect patente taxes at urban markets. It was through the negotiations between fiscal authorities, taxpayers, and state government that fiscal mechanisms based on "giro" were created. It was at the local level where the Fiscal Reform was finally legitimized.
\end{abstract}

Key words: Fiscal Reform; market; consumption and giro duties; fiscal authorities; taxpayers; urban markets.

Fecha de recepción: 3 de febrero de 2015 Fecha de aceptación: 8 de abril de 2015

Secuencia, ISSN 0186-0348, núm. 96 | septiembre-diciembre de 2016 | pp. 73-106 73

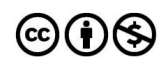




\section{La legitimidad de la reforma fiscal: autoridades tributarias y contribuyentes en el mercado de la ciudad de Veracruz, 1875-1889}

\section{Dora Sánchez Hidalgo Hernández}

\section{INTRODUCCIÓN}

E n 1878, don Luciano, un próspero comerciante del puerto de Veracruz, decidió abandonar su establecimiento que daba a la plaza del mercado de San Antonio. Un año después, un grupo de comerciantes establecidos amenazó al Ayuntamiento con seguir sus pasos. Entre las causas de su descontento estaban, por un lado, la incapacidad del gobierno local para mantener la plaza en buen estado y controlar a los comerciantes ambulantes y, por el otro, la falta de claridad en torno al cobro de los derechos municipales y los de consumo. Esta situación empezó a cambiar hacia 1886, cuando en los padrones comerciales se incrementó el número de establecimientos registrados como contribuyentes dispuestos a pagar derecho de giro. ${ }^{1}$ Tres años después, la tendencia de recaudación por derechos de giro aumentó notablemente, y cuando al fin se decretó la supresión de las alcabalas, el municipio cedió la recaudación de estos derechos al tesoro estatal. En el ám-

${ }^{1}$ Este artículo está basado en documentos oficiales preparados por el Ayuntamiento y en los informes de los gobernadores del estado de Veracruz. En estas fuentes pueden rastrearse las voces de los contribuyentes. En cuanto a la información del gobierno municipal, existen dos series de documentos: las notificaciones de establecimientos y los padrones de causantes de derechos de consumo. En estos registros los pequeños comerciantes establecidos enviaban cartas al Ayuntamiento con peticiones y quejas en torno al desempeño de las autoridades tributarias locales, como el tesorero municipal y los agentes recaudadores. Debido a que estos registros se levantaban cada cierto tiempo, sirven para mostrar cómo la organización y las funciones de estas autoridades fueron cambiando a lo largo de la reforma tributaria, entre las décadas de 1870 y 1890. La segunda serie de documentos empleados fueron los informes del regidor de mercados ante el Ayuntamiento. Todos estos registros están en el Archivo de Correspondencias del Archivo y Biblioteca Histórica Municipal de Veracruz (en adelante Aвнmv), México. 
bito federal esta transición de derechos de consumo a derechos de patente fue un éxito de la reforma tributaria, ya que representó un primer paso para sustituir los impuestos indirectos, ligados al comercio, por los directos, que gravaban el capital.

El presente artículo busca explicar dos cuestiones: primero, cómo los comerciantes y las autoridades tributarias lograron crear acuerdos in situ que permitieron el tránsito de gravámenes, y, segundo, qué implicaciones tuvo la prohibición de las alcabalas para el Ayuntamiento de Veracruz, como órgano de gobierno que tenía la facultad de organizar el comercio urbano en el proceso de modernización tributaria. Para responder a estas interrogantes, se hará un microanálisis de los conflictos en torno a la definición del cobro de derechos relacionados con el comercio, que surgieron entre distintos grupos de comerciantes, el Ayuntamiento y la tesorería municipal. Este trabajo dará una mirada desde lo local a los límites de la doctrina liberal. De esta manera, mi interés es llevar la discusión del ámbito de la ley al espacio donde esta se tradujo en la realidad práctica en tensiones, confrontaciones y negociaciones, que por lo regular se condujeron de manera eficaz en las dinámicas de comercialización en el puerto y la ciudad de Veracruz.

Por medio de este estudio se busca mostrar cómo la legitimidad del discurso de la reforma fiscal cobró sentido en los mercados urbanos; es decir, no sólo se trató de una medida impuesta por los diseñadores de la política tributaria en el ámbito federal, sino que fue el resultado de una serie de negociaciones entre distintos grupos de vendedores, revendedores, ambulantes y comerciantes establecidos con las autoridades encargadas de cobrar los impuestos. Sostengo que el tránsito del derecho de consumo al derecho de giro y, más tarde, al de patente, fue lo que permitió al Ayuntamiento mejorar la recaudación e incluir en los padrones a los nuevos comerciantes que satisfacían la creciente demanda en la ciudad. Para explicar cómo ocurrieron estas transformaciones, me centraré en tres puntos: 1) las tensiones para definir los ámbitos de operación de las distintas autoridades tributarias que podían ejecutar la ley. En un lugar como el puerto de Veracruz, este reacomodo institucional fue particularmente complicado debido a la convergencia de las jurisdicciones fiscales federales, estatales y municipales; 2) las formas de establecer los derechos e impuestos que deberían pagar los comerciantes y ambulantes $y$, a partir de esto, definir los canales para las contribuciones estatales, y 3) la capacidad de repuestas de las autoridades locales para aplicar los reglamentos en la vida cotidiana.

\section{()(1) $(9$}




\section{LOS NUEVOS RETOS PARA LA RECAUDACIÓN TRIBUTARIA EN EL AYUNTAMIENTO DE VERACRUZ ANTE LA RECONFIGURACIÓN DE LA ECONOMÍA REGIONAL}

A la par que los liberales tomaron el poder y establecieron acuerdos políticos con los conservadores, los mercados de consumo en la ciudad de Veracruz empezaron a expandirse. Mientras tanto, en varios cantones, como Oxuluama, Tantoyuca, Chicontepec, Tuxpan, Papantla, Misantla, Jalacingo, Xalapa, Coatepec, Huatusco, Córdoba, Orizaba, Veracruz, Zongolica, Cosamaloapan, Los Tuxtlas, Acayucan y Minatitlán, "se desenvolvía una economía local que preparaba el camino para iniciar el proceso de desarrollo comercial, agrícola e industrial" (Ordóñez, 2005, p. 39). Este impulso regional, junto con la pacificación de los caminos y el avance del ferrocarril, también aumentó la circulación de las mercancías importadas por el puerto a la región. En este contexto, la plaza de Veracruz no sólo era un centro de internación de mercancías hacia la ciudad de México y Xalapa, donde quienes llegaban del interior no sólo abandonaban el puerto inmediatamente después de comercializar su cargamento, sino que fue ahí donde inició una intensa competencia entre distintos comerciantes que luchaban en lo cotidiano para aprovechar las posibilidades abiertas por el comercio al menudeo. ${ }^{2}$ Además de vender en la plaza, este tipo de comercio también alimentaba la creciente demanda de los nuevos pobladores en los márgenes de la ciudad. Entre los minoristas estaban quienes tendían su petate en la plaza de San Antonio para revender diversos productos, aquellos que vendían semillas en sus establecimientos dentro del mercado y los dueños de tiendas de abarrotes y ropa,

${ }^{2}$ La importancia de las actividades comerciales en la ciudad se puede observar en el presupuesto de ingresos del Ayuntamiento, considerado en pesos. Los cuatro rubros más importantes en 1869 fueron los derechos de aguada sobre harinas (22 500); cobro por alumbrado público (21 700), impuestos a mercados (21 600) y el derecho municipal sobre efectos extranjeros (20 000). A estos los siguió la contribución por policía (12 000), los censos por fincas adjudicadas (9 738), el arbitrio de puertas (8 000), el arbitrio de consumo al menudeo (7 704), el consumo de agua del Jamapa (6 088), los arbitrios de licores al menudeo (6 054), derecho de aguada (2 000), alquileres por fincas en propiedad (1572), las multas (1500), el cementerio general (1450), los censos por obras pías (1397), el derecho de carruajes en ruedo (1 000), los juegos permitidos (1 000), los pisos en extramuros (850), derechos de venduta (500), diversiones públicas (200), pisos en la ciudad (110) y fiel contraste (50). La suma de los derechos de mercado, el derecho municipal sobre efectos extranjeros, los arbitrios de consumo al menudeo y el derecho de venduta es de 49804 . Memoria de trabajos municipales hechos en la ciudad de Veracruz en 1869. 1869. pp. 39-41. Aнвмv, México.

\section{(ㄷ)(1) $(3$}


mercerías o misceláneas (Estrada y Zenea, 1994, p. 4). Otros que se unían al comercio eran los vendedores ambulantes que llegaban desde Tlacotalpan, La Antigua, Medellín y Córdoba, a quienes se asignaban distintos días de la semana para acceder al mercado. A diferencia de Buenos Aires, donde había terrenos baldíos o "manzanas construidas" que servían como "plazas de carretas" (Salvatore, 2003, p. 25), en Veracruz todos los que quisieran vender tenían que hacerlo en el mercado, como ambulantes o en un establecimiento.

Claro que en una ciudad como el puerto, cuya vida a final de cuentas giraba en torno al comercio, había tenido siempre ambulantes. Lo nuevo dentro de las tendencias de liberalización en el ámbito local fueron las acciones de quienes organizaban el comercio en los mercados y las plazas. Estas acciones eran una respuesta a los cambios en las dinámicas de comercialización, que incluían el aumento y cambio de dirección de los flujos comerciales, la diversificación del tipo de mercancías y las interacciones entre quienes se daban cita en el mercado, desde los arrieros y campesinos, hasta los consignatarios y dueños de bodegas. En este contexto, los comerciantes en Veracruz buscaron influir en las decisiones del Ayuntamiento para regular el comercio. Por su parte, dicho órgano de gobierno quería conciliar sus intereses tributarios con la nueva legislación liberal, que establecía la abolición de las alcabalas y disponía nuevos mecanismos tributarios para canalizar las contribuciones federales. En el terreno cotidiano, las autoridades locales usaron los mecanismos fiscales para legitimarse como garantes de los derechos del libre mercado; de manera que los impuestos no sólo fueron mecanismos de recaudación que le permitían a la ciudad brindar servicios públicos, sino que también eran herramientas políticas para organizar las relaciones de producción, comercialización y consumo (Rodríguez, 1996, p. 146).

Al igual que en otros estados, los intentos del gobierno estatal de Veracruz por reformar las alcabalas afectaron la recaudación de los derechos municipales en las ciudades (Jiménez, 2001, p. 275). Si se buscaba sustituirlos por impuestos directos -al mismo tiempo que se quitaban las alcabalas-, el gobierno local se quedaría sin mecanismos para regular las dinámicas de comercialización en su ciudad. Por esta razón, podemos afirmar que no era una cuestión sólo de recursos, sino de gobernabilidad. La sustitución también le generaba problemas de administración al gobierno del estado, pues al eliminar las alcabalas tenía que buscar otra forma de canalizar los recursos tributarios a su erario mediante las contribuciones estatales. Mientras la recaudación por impuestos directos no aumentara, las contribuciones estatales concurrirían con los derechos municipales, especialmente con los de con-

\section{()(1) $(9$}


sumo. Para explicar la complejidad de este proceso, conviene aclarar en qué consistían los mecanismos recaudatorios locales.

En principio, los derechos municipales eran los ingresos que obtenía el gobierno local por el uso del espacio público; por ejemplo, por emplear el rastro, los mercados, los lugares para las ferias y la plazuela del muelle. La manera en que esos ingresos se asignaban en el presupuesto no se correlacionaba con ningún gravamen en específico; es decir, si un año la recaudación por el uso de mercados aumentaba, pero el Ayuntamiento decidía que era necesario invertir en mejoras al panteón, entonces los ingresos generados por derechos de mercados se destinaban al mantenimiento del otro espacio.

El derecho de mercado era lo que el comerciante debía pagar para tener un lugar en el mercado, sin importar que vendiera o no; por otra parte, el derecho por la transacción de compraventa se gravaba como derecho de consumo. Por último, la adjudicación era el derecho a cobrar por el uso de los propios municipales (terrenos o edificios), aunque estos siguieran siendo propiedad del gobierno municipal. Con las leyes de desamortización de 1856, el municipio otorgó este derecho de adjudicación a los ciudadanos, como concesionarios, rematantes o simplemente adjudicatarios. Estos, a su vez, podían arrendar dichos lugares para cualquier fin, siempre y cuando se hicieran cargo del mantenimiento. En el caso de los edificios del mercado de San Agustín, también había que pagar los derechos de mercado y consumo, además de los censos. La adjudicación, al ser un derecho municipal, no generaba $25 \%$ de la contribución federal, mientras el propio era el ingreso generado por el uso de esa propiedad, que seguía siendo del municipio.

Desde la colonia hasta mediados del siglo xIX, estos mecanismos recaudatorios habían funcionado bien para regular los flujos comerciales entre la ciudad y el puerto de Veracruz. Mientras la primera controlaba los derechos y obligaciones de los comerciantes que podían vender en sus mercados, el sistema de alcabalas regulaba qué tipo de bienes, productos y mercancías podían entrar y salir de esos mercados (Sánchez, 2009, p. 81). Este equilibrio cambió durante las guerras liberales, cuando las dinámicas de las redes que unían los circuitos mercantiles y los grupos de poder -sobre todo en los puertos-crearon nuevas alianzas aprovechando "las coyunturas políticas en un tiempo de amplia negociación entre las elites regionales y los cambiantes representantes a nivel nacional" (Gómez Cruz, 2012, p. 258). La ampliación y diversificación de estas redes regionales repercutieron en el poder de los actores comerciales que vinculaban los espacios de compraventa en el mercado urbano. En consecuencia, la relación del mercado y el estado no podía seguir igual.

\section{()(1) $(9$}


En el ámbito federal, las resistencias al cambio en el estado de Veracruz reflejaban los reacomodos de una vieja disputa entre los grupos de poder que controlaban las casas comerciales que unían a Veracruz con la ciudad de México y, por otro lado, las redes de comercialización regional. Sobre todo estaba el interés por controlar las compañías navieras (Blázquez, 2012, p. 60). En el ámbito de las ideas políticas el choque tuvo lugar en los congresos estatales. Si bien había acuerdos entre quienes abogaban por el libre intercambio, como el modelo que debía regular la relación entre el mercado y el Estado, no quedaba tan claro cómo garantizar la oferta de bienes públicos. Con la creación de presupuestos se tomaron decisiones que permitieron formar consensos acerca de qué autoridad tendría la obligación de recaudar los impuestos y, por lo tanto, el derecho de ejercer el gasto (Carmagnani, 1994). ${ }^{3}$ Pero los acuerdos en las legislaturas eran sólo una de las bases del proceso de formación de un aparato tributario, el otro fundamento necesario era la consolidación de la legitimidad de las autoridades tributarias que le dieran sustento a la ley desde lo local.

\section{EL PAPEL DE LAS AUTORIDADES TRIBUTARIAS LOCALES EN EL ROMPIMIENTO DE LAS RESISTENCIAS A LA ABOLICIÓN DE LAS ALCABALAS DURANTE LA REFORMA FISCAL DEL SIGLO XIX}

La reconfiguración de los mercados urbanos en la ciudad-puerto de Veracruz fue parte de los procesos de modernización fiscal emprendidos por la elite política durante la primera mitad del siglo xix. En esta corriente de cambio, tanto conservadores como liberales pensaban que el comercio debía ser el motor del desarrollo manufacturero e industrial (Márquez, 1998, p. 407). Lograr este objetivo requirió alcanzar consensos para reformar las leyes que regulaban el tránsito y comercialización de productos y mercancías en el territorio nacional. Como señala Ernest Sánchez Santiró, las posiciones a favor de la sustitución de las alcabalas por contribuciones directas se perfilaron a lo largo de la primera mitad del siglo xix: "La propia diversidad socioeconómica del país, el recuerdo de las diferentes experiencias de reforma fiscal, el

${ }^{3}$ Es importante especificar que para el caso de Veracruz en el siglo xIx no se encontraron los diarios de debates del Congreso estatal. Sin embargo, dos fuentes muy útiles para superar esta carencia fueron la colección de leyes y decretos y los informes de los gobernadores.

\section{()(1) $\$$}


posicionamiento de las elites regionales y la fuerza de las distintas opciones políticas en las entidades federativas serían algunos de los elementos que iban a marcar la implementación de las contribuciones directas" (Sánchez, 2009, p. 245).

Se han estudiado mucho las razones que llevaron a los liberales a moderar la reforma económica. Una justificación para hacerlo fue la imposibilidad de crear mecanismos tributarios para recuperar los ingresos que se dejarían de recaudar por las alcabalas. El diseño de impuestos directos que facilitaran la recaudación, así como la redistribución fiscal de las contribuciones estatales, dependía, en gran medida, de sustituir los derechos al consumo, ya que también gravaban al comercio. De nada serviría abolir las alcabalas si se continuaba tasando el consumo en los mercados urbanos. Pero los derechos al consumo eran el ingreso municipal más importante y regulaban los flujos de comercio regional en las ciudades. En este contexto, las resistencias al cambio se debieron a que se postergaron las propuestas para que los impuestos indirectos fueran de la federación y los directos de los estados, ante "la estructura confederal del régimen político mexicano decimonónico y la ausencia de un pacto entre el poder central y las elites locales" (Gómez y Kourí, 2010, p. 85).

En esta condición geopolítica, los derechos de consumo eran una herramienta de gobierno para los Ayuntamientos. Por lo anterior, las resistencias al nuevo sistema tributario por parte de las elites locales a lo largo del siglo xIx también provinieron de una dimensión política, y no sólo de factores comerciales, económicos o de producción. Ahondar desde lo político en el conocimiento del porqué de las resistencias, es una aproximación al proceso de federalización que se pretendía promover con la reforma económica, en función de que "la resistencia al cambio, la omisión que entorpece otras voluntades, constituye también una decisión...” (Rodríguez, 1996, p. 106). Más allá del conflicto entre las elites regionales y el centro, habrá que estudiar entonces la posición del Ayuntamiento frente a sus contribuyentes, pues es ahí donde se pueden encontrar las razones de esas resistencias. Hacerlo implica analizar la interacción extractor/contribuyente sobre la cual, en última instancia, se construyó la legitimidad de la reforma, logrando romper con ello las resistencias en el ámbito federal (Rhi Sausi y Molina, 2014, p. 29).

En la historiografía, un camino para el análisis de la reforma fiscal ha sido el estudio de las alcabalas como concepto del pensamiento económico de la época y como objetivo de la reforma. En el caso de la segunda mitad del siglo xIX, los promotores de la abolición de las alcabalas en muchos casos fue-

\section{()(1) $(9$}


ron también quienes empezaron a escribir la historia fiscal (Jáuregui, 2003, p. 736). En principio su intención era sustentar sus argumentos en pro de la reforma ante la "necesidad" histórica de los cambios. Desde esta lectura, la producción historiográfica de ese periodo entendería la reforma como una lucha ideológica entre modernidad y herencia colonial justificada por la historia. Lo mismo podría decirse entonces del trabajo historiográfico posterior, en el que la tensión se extiende al porfiriato y al periodo posrevolucionario. La historia parece confirmar que la alcabala era un freno para la integración del mercado interno; sin embargo, ante la imposibilidad de crear otros mecanismos recaudatorios, su permanencia se aceptó como un mal necesario.

Ante la longevidad del impuesto de alcabalas y el perpetuo intento de sustituirlas que las acompaña, es imposible negar que la historiografía debe ir más allá de la comprensión de una reforma nunca alcanzada (Jáuregui, 2003, p. 775). Para salir de este punto muerto, los historiadores económicos han estudiado la reforma tomando como fuente este impuesto para explicar cómo funcionaba el mercado. Esta aproximación ha demostrado cómo los cambios en el sistema fiscal y en la administración tributaria que se buscaron en cada periodo respondían a la reconfiguración del espacio económico a partir del orden político que regía la interacción tributaria entre los distintos niveles de gobierno. A lo largo del siglo xIx, los estados admitieron cobrar impuestos liberales, pero no dejaron de recaudar muchos del antiguo régimen, como el de consumo. Lo que ha cambiado es la pregunta, no se trata de buscar por qué no fue posible abolir la alcabala y modernizar el sistema tributario, sino saber qué tipo de impuesto era, cómo funcionaba y qué revela del mercado que regulaba.

En este sentido, varios estudios sobre el periodo colonial se centran en la integración del mercado interno regional para explicar las dinámicas comerciales en el mundo rural y la participación de los indígenas en las zonas productivas. Esto permite analizar los procesos de crecimiento y dispersión para reflexionar sobre el significado de la independencia o "autonomía" del mercado interno en relación con la metrópoli. Otros trabajos que se enfocan en la relación de la política alcabalatoria con los mercados regionales han demostrado que el cobro de dicho impuesto afectaba al consumo, pues su costo se trasladaba del comerciante al consumidor (Rhi Sausi y Molina, 2014, p. 23).

Cuando se toma la perspectiva de la ciudad, la riqueza de los registros municipales de recaudación tributaria en los mercados también ha abierto rutas importantes para explicar el impacto de las alcabalas en el sistema fiscal. Por ejemplo, el estudio de los centros urbanos, en específico de sus mercados,

\section{()(1) $(3$}


ha demostrado su papel como núcleos de distribución e intercambio, desde donde se impulsaban las redes de distribución en sus estados, lo que a su vez los conectaba con el mercado internacional (Hernández, 2006, p. 223). Recientemente, un estudio sobre la ciudad de Veracruz se enfoca en el significado de los cambios de la política fiscal de los derechos municipales en las ciudades; es decir, en las jurisdicciones de los Ayuntamientos y su relación con los contribuyentes urbanos. Una conclusión a la que se llegó es que las estrategias recaudatorias en ese nivel de gobierno -sobre todo en la redefinición de su interacción con los contribuyentes- permitieron al Ayuntamiento tener cierta autonomía frente a la corona y las autoridades imperiales (Celaya, 2014, p. 38).

Ha resultado más difícil estudiar la relación que hubo en el siglo XIX entre contribuyentes, gobierno local y las autoridades tributarias (Rhi Sausi y Molina, 2014, p. 14). Esto se debe en parte a la falta de fuentes documentales, como resultado de la debilitada administración federal en el periodo, así como a la incapacidad de los mismos gobiernos locales para levantar padrones y censos confiables, situación que se refleja en los archivos históricos. Sin embargo, varios estudios regionales han podido profundizar en esta dirección, desde lo local han demostrado que los suelos tributarios entre las entidades federativas dividían zonas productivas, lo cual generaba fuertes conflictos entre productores y comerciantes, que derivaron en una férrea defensa de la soberanía estatal en torno a los impuestos a la compraventa (Rhi Sausi y Molina, 2014, p. 106). Para las alcabalas posporfirianas, Luis Aboites (2001) argumenta que la continuidad en la defensa de la soberanía local desde los estados, precisamente en lo que se refiere a la "renuencia local a sumarse al ISIM [impuesto sobre ingresos mercantiles] era la condición esencial de la existencia de las alcabalas" (p. 373).

Esta literatura ha demostrado que los obstáculos para reformar las alcabalas influyeron la relación entre el crecimiento y el estancamiento de la producción. En este contexto, el estado de Veracruz fue uno de los promotores más activos a favor de la desaparición de ese impuesto, por considerarlo una de las causas de la doble tributación que obstaculizaba la expansión del mercado interregional (Blázquez, 1986, p. 2919). De hecho, en los intentos por regular la comercialización en los mercados urbanos, el gobierno municipal y el estatal coincidían en dos puntos: por un lado, en que la política tributaria debía evitar la sobrecarga fiscal y la doble tributación y, por otro, que las contribuciones federales distorsionaban los precios al consumidor final. Quien sintetizó más claramente la reforma impulsada por el estado de Veracruz fue el gobernador Juan de la Luz Enríquez, quien gobernó dos periodos

\section{(1)(1) $\$$}


seguidos, entre 1884 y 1892. En el informe que presentó ante el Congreso en septiembre de 1886 dijo:

[...] partidario como el que más de la libertad del comercio interior, como que comprendo que el absurdo sistema de tributos alcabalatorios heredado del régimen colonial, sofoca todo los ramos de industria, paraliza las transacciones, detiene el desarrollo de la riqueza pública, e impone grandes sacrificios a los pueblos, mayores que los debidos, por los excesivos costos de recaudación inherentes a dichos sistemas, desde que me encargué del ejecutivo todas mis tendencias se han encaminado a realizar la reforma de las leyes tributarias del estado en el sentido de poner completamente libre el tráfico interior (Blázquez, 1986, p. 2367).

En esta cita podemos identificar que los objetivos de la reforma fiscal para Enríquez eran impulsar la industria y el desarrollo económico; crear un mercado interregional para expandir el mercado interno; desaparecer la distorsión de precios al consumidor final, y evitar el déficit fiscal de los municipios. Para lograr sus objetivos, el gobernador reconocía en este mismo informe las dificultades de abolir simultáneamente las alcabalas de tránsito y de los derechos de consumo cobrados al introducir las mercancías en las poblaciones (de portazgo). Por si fuera poco, el mandatario resaltaba que había una serie de impuestos especiales sobre bultos. Así es que, aun cuando en marzo de 1887 se hizo efectiva la abolición de las alcabalas, de acuerdo con la ley número 77 del 17 de diciembre de 1886, estaba seguro de que estos cobros seguirían generando el mismo efecto de una alcabala. En este sentido, el gobernador señalaba que precisamente en las ciudades con mayor actividad económica era donde el derecho de consumo seguía utilizándose como un impuesto al tránsito, como Veracruz, Orizaba, Jalapa, Córdoba y Tlacotalpan, todas en la región central del estado. A pesar de los retos, Enríquez continuó con ánimos, pues aclaró que "fuera de las pocas poblaciones en donde se tropezó con esas dificultades, en todas las demás se llevó a cabo el cambio rentístico sin el menor perjuicio" (Blázquez, 1986, p. 2941).

Al igual que el gobernador, en la historiografía tampoco se ha profundizado en lo que pasaba con los derechos de consumo en las ciudades, especialmente entre 1870 y 1890 . Pero desaparecerlos siguió siendo una prioridad de la reforma en los mercados urbanos. Esto no sólo en términos de recaudación para el erario local, sino porque eran clave para liberar el comercio que impulsara la industria en el estado, tanto por el tránsito de insumos

\section{()(1) $(9$}


para la producción y la manufactura, como para mantener la competitividad de los productos importados que se consumían localmente y que pretendían circular hacia el mercado regional. Sin embargo, en este punto la discusión historiográfica deja fuera el análisis local y vuelve a centrarse en los problemas que trajo la sobreimposición de un sistema federal fiscal, el cual buscaba sustituir la herencia colonial de la recaudación indirecta y centralizada, por una directa y federal.

Para explicar si la eliminación de las alcabalas representó un cambio profundo en el sistema fiscal federal (y en el significado de la modernidad de los mecanismos de recaudación), es necesario estudiar no sólo la tensión entre federación y estados, sino la relación de estos últimos -a través de los agentes tributarios- con los contribuyentes, ya que fue en ese ámbito donde se negoció la legitimidad de la reforma (Rhi Sausi y Molina, 2014, p. 180). Debido a que esta legitimidad se construyó en el ámbito estatal, me parece importante rescatar los aportes de los estudios coloniales en términos de la ciudad como el núcleo que vinculaba las redes regionales del mercado interno. Es importante estudiar lo que pasó en la ciudad a partir de 1870, porque fue ahí donde tuvo lugar la confrontación entre los extractores de impuestos y los contribuyentes cuando cambió la lógica tributaria, de los impuestos indirectos (al comercio) a los directos. Específicamente, aquí me interesan los pequeños comerciantes (establecidos y ambulantes), aquellos que estaban al inicio de las redes de comercialización entre los productores, transportistas e introductores y el consumidor final en la ciudad. Por otra parte, la influencia de los gobiernos estatales en los ayuntamientos permitió establecer los canales de comunicación política para controlar la recaudación y redistribución de los ingresos por giro de patente. Sobre las capacidades de los ayuntamientos, Rodríguez Kurí (1996) discute cómo en la ciudad de México, a partir de la experiencia de gobierno durante el siglo xix, las atribuciones de esta autoridad salieron del ámbito de servicios, mejoras urbanas y vigilancia, cuando el sentido de la policía urbana se relacionó directamente con las ideas de contar con un mejor gobierno como un interés público. Fue en función de esa experiencia de gobierno que "surgieron procesos de definición de actores, argumentos y procesos que convergen en la constitución de la autoridad legítima" (p. 40).

Un problema en los procesos de definición a que se refiere Rodríguez fue que si bien la alcabala era un impuesto estatal, también concurría fiscalmente con los municipios, por lo que ambas entidades de gobierno tenían la facultad de gravar la misma fuente, el tránsito comercial, y al tener el dere-

\section{()(1) $(9$}


cho de cobrarlo podían incluirlo en sus ingresos y ejercerlo en su gasto. La discordia estaba en que al desaparecer el impuesto de alcabala, estas entidades tuvieron que buscar otras formas de sustituir dichos recursos fiscales, por lo cual tuvieron que definir cuál sería la fuente de los gravámenes. El sistema fiscal debía hacer más eficientes los canales de redistribución de ingresos tributarios a través de las contribuciones federales. Esta situación planteó serios desacuerdos en dos sentidos: primero, en el ámbito federal no estaba claro cuáles serían los derechos de los estados y cuáles los del Ayuntamiento; segundo, en el ámbito local, el Ayuntamiento entró en conflicto con los comerciantes al diseñar nuevos mecanismos de recaudación como parte de la reforma fiscal impulsada por los gobiernos liberales. Me refiero específicamente a la aplicación de los reglamentos de cobro en la vida cotidiana del mercado y a las formas de establecer las tarifas que deberían pagar los comerciantes, tanto ambulantes como establecidos. En la solución de estos desacuerdos se definieron los ámbitos de operación de las distintas autoridades tributarias que convergían en los mercados urbanos: los regidores de mercados del Ayuntamiento, el tesorero municipal y el jefe político.

Con una visión politológica, autores como Mauricio Merino (1998) han señalado que fueron estas autoridades las que llevaron a cabo "la edificación de la maquinaria estatal, que se desplegara en varios frentes para articular al gobierno nacional con las instituciones políticas locales, tomándolas como el soporte de la dominación sobre el territorio [...] [ya fuera con base en las] alcabalas [...] o en las atribuciones de gobierno concedidas a los jefes políticos que dirigían la administración del territorio" (p. 25). Partiendo de esta hipótesis, Merino argumenta que las reformas tributarias fueron un elemento central y las alcabalas funcionaron como un "aparato administrativo". Además, sostiene que las autoridades locales controlaron dichos aparatos hasta lograr establecer un equilibrio entre las prácticas cotidianas y las formas jurídicas para diferenciar los impuestos federales de los estatales. De acuerdo con Merino (1998) esta fue la "época de oro en los gobiernos locales mexicanos, ese periodo sólo pudo desplegarse gracias a la ausencia del Estado nacional" (p. 26). Desde que Merino escribió este libro, hace casi 20 años, los historiadores hemos investigado poco acerca de cómo funcionaban esos aparatos administrativos locales, más allá de la operatividad de la burocracia tributaria. Ante este vacío, es difícil saber cómo se estructuraron las estrategias argumentales que permitieron que las autoridades tributarias se constituyeran como la autoridad legítima. Si bien fue en el porfiriato cuando se logró la consolidación de ese Estado nacional "centralizado", comprender

\section{(1)(1) $\$$}


cómo se logró dicha meta requiere explicar, desde una perspectiva históri$\mathrm{ca}$, el funcionamiento de lo que Merino llama aparatos administrativos que dieron paso a la jerarquía recaudatoria en medio de la integración a los sistemas de libre mercado mundiales. Esto implica aclarar los conflictos entre los ayuntamientos y el gobierno federal por regular la recaudación tributaria en los mercados urbanos cuando la lógica de las alcabalas cambió. Lo anterior se vuelve necesario, sobre todo si pensamos que al concluir la época de oro de los gobiernos locales, estos ya habían sentado las bases sobre las que se diseñó un pacto federal entre las elites, mediante el cual se redistribuyeron los recursos tributarios una vez que se consolidó el Estado mexicano (Carmagnani, 1994, pp. 165-166). Se requiere entonces explicar no sólo la definición de los ámbitos de acción de esas autoridades locales, sino de sus estrategias argumentales en el contexto de los cambios socioeconómicos que se estaban viviendo en el mercado, en un punto de convergencia de intereses muy diversos. En esta dirección, el estudio del tránsito del derecho de consumo al de patente permite ver cómo se negociaron los mecanismos de recaudación en la reforma fiscal, sin verlo como un impuesto "ilegal" o "práctica antigua". Desde esta perspectiva, se podrá comprender qué mecanismos fueron los que permitieron romper las resistencias a los cambios implicados en la reforma mediante nuevos canales de redistribución tributaria.

A continuación analizaré dos conflictos que tuvieron lugar en la plaza del mercado más importante de la ciudad de Veracruz. El primero se desató cuando el gobierno quiso aumentar $25 \%$ el derecho de adjudicación para canalizarlo a la contribución federal, con base en la ley estatal de Hacienda de 1861. El segundo conflicto surgió entre adjudicatarios, vendedores ambulantes y revendedores, cuando el regidor de mercados de la ciudad buscó incrementar $50 \%$ las cuotas diarias por derecho de mercado.

\section{REGIDORES, COMERCIANTES AMBULANTES Y ESTABLECIDOS EN BUSCA DE MECANISMOS RECAUDATORIOS EN LA PLAZA DEL MERCADO DE SAN ANTONIO}

\section{Derecho de adjudicación}

En 1873, el regidor de la tesorería presentó ante el Ayuntamiento la problemática generada por la falta de claridad en el "cobro de plaza por puestos de

\section{()(1) $(9$}


vendimias". ${ }^{4}$ De acuerdo con el regidor, la Ley de Hacienda del 16 de diciembre de 1861 no dejaba claro si dicho cobro se incluiría dentro de los impuestos que serían recargados con $25 \%$ de la contribución. Según los mecanismos de recaudación del Ayuntamiento, el derecho de mercado (en este caso el cobro de plaza por puesto de vendimia) no era una contribución directa, sino un derecho municipal por arrendamiento del espacio ocupado para la venta. Un contratista o rematante cobraba el impuesto que se establecía por el uso del local para la vendimia en un día, que generalmente era de uno a dos pesos. El problema para el regidor era que el artículo $7^{\circ}$ de dicha ley especificaba que en "los casos de remate o arrendamiento de cualquiera contribución o renta de los estados o municipios, el arrendatario pagará la contribución federal sobre la suma del arrendamiento". 5

Si el cobro del impuesto se hacía sobre el derecho al lugar y al día en que el vendedor tenía acceso al mercado, entonces dicho impuesto continuaría siendo una fuente de recaudación para el gobierno local; si era sobre el derecho a cobrar una contribución de los estados o municipios, los ingresos estarían gravados con la contribución federal. Sin embargo, según la misma ley, si la cuota cobrada era menor de cuatro reales la contribución "no incluía los impuestos de plaza que se cobraban en el mercado". El regidor concluía que "en el espíritu del legislador" seguramente la única intención era "favorecer a los expendedores del mercado y a los consumidores en general que compran los frutos allí vendidos sin el gravamen de contribución". ${ }^{6}$ De gravarse con el $25 \%$ correspondiente para la contribución estatal, el regidor preveía que los contratistas o arrendatarios que cobraban por el derecho de mercado trasladarían el costo a los comerciantes, lo cual generaría descontento entre estos últimos, afectando con ello la recaudación del Ayuntamiento. Su argumentación para evitarlo iba acorde con dos principios liberales: evitar la afectación de precios y la doble tributación. De este modo, el contratista que cobrara a distintos comerciantes por su derecho de mercado -es decir, por el lugar que ocupaban ya fuera en la plaza o en algún establecimiento-debía hacerlo por menos de cuatro reales; entonces, él no

${ }^{4}$ Cobro de plaza por puestos de vendimia, 1873-1874. Archivo de Correspondencia. Caja 254, vols. 358-359, fs. 739-745. Авнмv, México.

${ }^{5}$ Cobro de plaza por puestos de vendimia, 1873-1874. Archivo de Correspondencia. Caja 254, vols. 358-359, fs. 739. Авнмv, México.

${ }^{6}$ Cobro de plaza por puestos de vendimia, 1873-1874. Archivo de Correspondencia. Caja 254, vols. 358-359, fs. 739. Авнмv, México.

\section{()(1) $(9$}


debía pagar $25 \%$, pues no se trataba del derecho a recaudar, sino del derecho a tener un lugar en el mercado.

Un segundo punto en la tercera fracción del artículo $7^{\circ}$ hacía aún menos congruente la inclusión del cobro de plaza por vendimia en la contribución federal. Esta situación generó dificultades para establecer la diferencia entre derechos de consumo y mercancías de tránsito. Dicha fracción especificaba que "todos los efectos que no sean de primera necesidad e introducidos en hombros a las poblaciones por las personas pobres para venderlas en los mercados, causan y pagan la contribución federal en la alcabala". Para el regidor en Veracruz este no era el caso de los vendedores en el mercado, pues la mayor parte de los efectos (sobre todo de primera necesidad como alimentos) entraban vía marítima por cabotaje, paileboats, canoas y lanchones, o los traían los famosos arrieros y quienes llegaban en el tren a la estación de San Juan. El problema era que estos intermediarios o comisionistas pagaban el porcentaje del derecho municipal, ya fuera en el puerto, por uso de muelle o como derecho de portazgo. Además, su mercancía, aun cuando fuera de primera necesidad, también estaba gravada por los derechos de mercados, pues pagaban por vendimia al tener un lugar en el mercado. De manera que aun cuando los introductores y transportistas no vendían "directamente" al consumidor en la plaza, sino a los vendedores que tenían acceso al mercado, la mercancía estaba de igual forma gravada dos veces, sobre todo la que entraba por los muelles.

Esta situación era aún más grave si el contratista que cobraba a los vendedores por vendimia o a los arrendatarios de un lugar en el mercado tenía que pagar el porcentaje de la contribución federal. ${ }^{8}$ De acuerdo con el regidor, lo más lógico sería que el contratista del cobro del derecho de mercado transfiriera a los comerciantes y/o a los arrendatarios $25 \%$ de la contribución federal. Además, es interesante señalar que en los documentos existe una confusión en relación con el cobro de los derechos municipales, pues el regidor se refiere constantemente a la contribución federal cuando en realidad formaban parte de la Ley de Hacienda de 1861, que era estatal.

La preocupación central del regidor de la tesorería municipal era armonizar los mecanismos recaudatorios con la ley hacendaria de 1861 para

${ }^{7}$ Cobro de plaza por puestos de vendimia, 1873-1874. Archivo de Correspondencia. Caja 254, vols. 358-359, f. 740. ABHmv, México. Cursivas mías.

${ }^{8}$ Cobro de plaza por puestos de vendimia, 1873-1874. Archivo de Correspondencia. Caja 254, vols. 358-359, f. 740. Авнmv, México.

\section{()(1) $\$$}


liberar los derechos de mercados de las contribuciones federales. Para defender su posición sostuvo que el dinero recaudado por el arrendamiento "se destinaba a reparaciones, conservación, aseo de edificios construidos especialmente para mercados, fuentes y calzadas utilizadas precisamente por los expendedores". ${ }^{9}$ De ahí que el cobro de derecho de mercado no debía considerarse una contribución federal, sino un arrendamiento del Ayuntamiento, pues era el tesoro municipal el encargado de distribuir estos recursos para el mejoramiento de la ciudad. De lo contrario, el Ayuntamiento se quedaría sin una importante fuente de recursos para cumplir con sus funciones básicas de gobierno. En este panorama el regidor de la tesorería se preguntaba cuál sería la posición de aquellos a quienes se les aumentaban los impuestos como contribución federal, quienes además eran los principales beneficiados del mantenimiento del edificio. Debido a esta situación, el regidor solicitaba al supremo gobierno que la recaudación la hiciera la municipalidad como cobro de plaza por puesto de vendimia, el cual estaba "exceptuado de la contribución federal" en la $2^{\circ}$ fracción del artículo $6^{\circ} .^{10}$

En cuanto a las dinámicas de comercialización, en específico la internación de mercancías y productos a la ciudad, el regidor tocó tangencialmente un punto de tensión que sería crucial para negociar otros conflictos del mercado: la ambigüedad de la ley hacendaria de 1861 para definir quiénes estarían exentos de pagar con base en su condición de pobreza, en alusión a aquellos que entraban al mercado con sus mercancías en hombros. En principio esto pudo haber sido una estrategia para igualar las condiciones de competencia entre los comerciantes. Sin negar esta intención de la ley, en Veracruz su efecto tiene que estudiarse en el contexto de los reacomodos tributarios en la aduana portuaria, en especial en relación con las facultades del jefe político para cobrar la internación -en el muelle y en las puertas de la ciudad-de mercancías y productos por bulto como parte de los derechos de consumo municipales. La ley para tasar los derechos de consumo para mercancías nacionales dificultó las tareas de recaudación para esa autoridad, pues dependía de si los artículos estaban de tránsito o se consumían en el lugar (Colección, 1920, Ley número 173, p. 170). Esta ley dirigida a las mercancías nacionales no especificó cómo tasar la venta en los mercados públicos; la única forma de gravarlas era

9 Cobro de plaza por puestos de vendimia, 1873-1874. Archivo de Correspondencia. Caja 254, vols. 358-359, f. 741. Авнмv, México.

${ }^{10}$ Cobro de plaza por puestos de vendimia, 1873-1874. Archivo de Correspondencia. Caja 254, vols. 358-359, f. 741. Авнмv, México.

\section{()(1) $(3$}


mediante el cobro al puesto de vendimia. Además, tampoco se aclaraba cómo se cobraría a los ambulantes y revendedores cuando se abastecieran (o fueran ellos quienes abastecían) con los comerciantes establecidos o cuando no fueran ellos quienes llegaban a la ciudad con los bultos en hombros. ${ }^{11}$

Ante este vacío, el Ayuntamiento apeló nuevamente al derecho de vendimia para tasar a los comerciantes con base en el espacio, horario y condición socioeconómica. Sin embargo, esta autoridad especificó que al no tener injerencia para solucionar los abusos en las alcabalas fuera de su jurisdicción o en los muelles, su obligación se limitaba a cumplir con el cobro de derechos de mercado para garantizar la "justa competencia". ${ }^{12}$ De manera que al reducir la presión fiscal a la que estaban expuestos los comerciantes, logró legitimar su estrategia y excluir estos impuestos locales al comercio, es decir, $25 \%$ no sería transferido al erario del estado.

\section{Cuotas diarias por derechos de mercados}

A lo largo del siglo xix la responsabilidad del Ayuntamiento ante los adjudicatarios, revendedores y vendedores ambulantes se fue modificando como resultado de las tensiones entre los distintos actores que convergían en los mercados urbanos. La historia de la construcción del mercado de San Antonio, antes plaza de San Agustín (por pertenecer al ex convento del mismo nombre), muestra cómo la lucha por el espacio cambió la percepción de los derechos y obligaciones para comerciar. En la posguerra, los gobiernos liberales más moderados aceptaron que el Estado tendría la obligación de brindar una oferta de bienes públicos (Carmagnani, 1994, p. 369). Un objetivo era animar a que los individuos invirtieran en sus negocios. En cambio, los dueños de los establecimientos dentro del mercado argumentaban que mientras el gobierno garantizara que los vendedores y revendedores en la plaza no obstaculizarían los ritmos de los flujos de mercancía, ellos se encargarían del mantenimiento del edificio. Si ellos cumplían con el pago de derechos e impuestos, entonces la obligación del Ayuntamiento era mantener un movimiento

${ }_{11}$ Cobro de plaza por puestos de vendimia, 1873-1874. Archivo de Correspondencia. Caja 254, vols. 358-359, f. 740. Авнmv, México.

${ }^{12}$ Esta era la noción que los comerciantes usaban en sus quejas y peticiones para justificar, por un lado, la legitimidad de su demanda y, por el otro, la obligación que tenía el gobierno de defender los principios liberales del libre tránsito que sustentaba la abolición de las alcabalas.

\section{()(1) $\$$}


en la plaza que permitiera el equilibrio entre la oferta y la demanda. Este argumento se basaba, precisamente, en las ideas liberales del libre tránsito.

Como se explicó más arriba, el Ayuntamiento había garantizado el acceso a diferentes comerciantes según sus productos, procedencia, días de la semana, horarios o lugares específicos en que se ubicaban, con base en el cobro de los distintos derechos locales. Sólo cuando el gobierno empezó a presionar con aumentar los derechos municipales de consumo y mercado -al mismo tiempo que no desaparecía el cobro de las alcabalas-, los comerciantes volvieron a apelar a la obligación del Ayuntamiento de mantener en buenas condiciones los edificios públicos. Esta posición los confrontó con los vendedores ambulantes y los revendedores cuando el regidor de la tesorería municipal anunció que aumentaría 50\% a la suma cobrada diariamente a los locales en la plaza del mercado. ${ }^{13}$ En principio esta era otra forma de recuperar las pérdidas al erario por dejar de cobrar el derecho de portazgo.

La confrontación por este aumento a los locales surgió ante los intentos por controlar la operatividad de las redes comerciales entre quienes vendían en la plaza y los locatarios. Este caso muestra cómo dichas redes se transformaron cuando la competencia entre los vendedores, revendedores y locatarios aumentó las tensiones por la distribución espacial del mercado. Por ejemplo, los comerciantes que habían adquirido el derecho a usar estos locales eran adjudicatarios, y eran parte de los propios del municipio. $\mathrm{Mu}^{-}$ chas veces estos rentaban el local a alguien más y otras eran ellos quienes vendían ahí sus mercancías o usaban el local como bodega. Más arriba se explicó que los adjudicatarios debían pagar los derechos municipales y de consumo o, si subarrendaban, debían recaudar dichos derechos. Cuando se quiso aplicar el aumento de 50\% a quienes estaban dentro del mercado, fueran adjudicatarios o arrendatarios, estos se negaron, pues ya pagaban los censos, los servicios de agua, el alumbrado y la limpia.

En los alegatos con el regidor de la tesorería se puede apreciar que la situación se complicaba aún más cuando los dueños o arrendatarios de los locales también vendían o compraban, usando a los revendedores de la plaza como intermediarios y delegándoles el pago de consumo y mercado. ${ }^{14}$ Estos

${ }^{13}$ Solicitud de los revendedores del mercado para revocar el aumento de $50 \%$ al pago diario del local. 28 de marzo de 1878. Archivo Correspondencia. Caja 270, vol. 378, fs. 211-233. АвнмV, México.

${ }^{14}$ Solicitud de los revendedores del mercado para revocar el aumento de $50 \%$ al pago diario del local. 28 de marzo de 1878. Archivo Correspondencia. Caja 270, vol. 378, fs. 222. AвнmV, México.

\section{()(1) $\$$}


últimos fueron los primeros en oponerse al aumento de la cuota. ${ }^{15}$ Su estrategia era intermediar y redistribuir la mercancía que compraban a los comisionistas, pero en la transacción ellos pagaban sus cuotas diarias. El problema era que si aumentaban en 50\% las cuotas al local, su negocio dejaba de ser viable, pues en cierta forma se les transfería el costo que los dueños de los locales no querían absorber. Por ello alegaron ser parte de la pequeña industria y consideraron que no era "justo" que se les aumentara dicha cuota en los derechos de mercado, cuando ya pagaban los de consumo. ${ }^{16}$

De aumentar el cobro de derechos de mercado, otros afectados serían los vendedores ambulantes, quienes acabaron por unirse a los revendedores y expusieron juntos su caso ante el gobernador. Como reconocían que "los ciudadanos del Ayuntamiento, padres del pueblo, tal vez por sus graves ocupaciones no habrán podido enterarse de la situación que guardamos [...]", creían necesario informarle acerca de las cuotas que debían cubrir diariamente:

se ha introducido una aduana ambulante donde se cobra por toda introducción de toda clase de efectos de primera necesidad, pues pagamos un real por cada tercio de frijol, arroz, papas, frutas y legumbres. Además los derechos que se satisfacen en la aduana terrestre de dos reales por cada arroba de arroz. Cada huacal de huevos pagamos uno y medio reales de introducción y dos reales por cada uno de gallinas, y como es natural, luego que empezamos a vender al menudeo pagamos uno y medio por huacal de huevo y dos por el de gallinas. Por nuestros puestos botados a la intemperie, pagamos entre dos y tres reales diarios, por casillas forradas de lonas y puestos provisionales de semillas pagamos dos reales diarios, de frutas y legumbres medio real de introducción y un real diario por menudeo. ${ }^{17}$

15 Ocurso presentado por comerciantes en relación con la ley de contrabando. 1878. Archivo Correspondencia. Caja 283, vol. 392, fs. 699-714. Авнмv, México.

${ }^{16}$ Argumentaban que sus ventas oscilaban entre seis $y$ ocho pesos diarios y calculaban $25 \%$ de utilidad; es decir, un peso con cincuenta centavos y dos pesos, respectivamente; como aún debían sacar de esta utilidad el dinero para las cuotas diarias, pensaban que dicho aumento era excesivo. En una carta se quejaban contra "los españoles que solicitan destruir [su] pequeña industria sin reflexionar que a estos mismos les compramos los efectos y que los enriquecemos porque nuestras compras en pequeño sufren el recargo de un 12 y quizá un 25\%". Solicitud de los revendedores del mercado para revocar el aumento de $50 \%$ al pago diario del local. 28 de marzo de 1878. Archivo Correspondencia. Caja 270, vol. 378, f. 227. AвHmv, México.

${ }^{17}$ Solicitud de los revendedores del mercado para revocar el aumento de $50 \%$ al pago diario del local. 28 de marzo de 1878. Archivo Correspondencia. Caja 270, vol. 378, f. 222. Авнмv, México. Cursivas mías.

\section{()(1) $\$$}


Debido a que venían de "tierras lejanas a exponer nuestra mercancía a este inclemente clima", aprovecharon la carta para pedir que se construyeran dos naves de mampostería en el centro de la plaza, y que los munícipes terminaran los trabajos de ornato y la construcción de una fuente, pues le haría "bien a los que sufrimos desde hace muchos años la inclemencia del tiempo debajo de los aguaceros y de los rayos abrasadores del sol”. Por último, recordaban al gobernador que en esa "plaza sólo pagaba cada petate o puesto tendido de dos varas, medio real sin distinción de efectos". ${ }^{18}$ A pesar de las quejas, las tarifas se aumentaron y el gobernador del estado sólo mandó pedir una lista en la que se especificaran todos los derechos cobrados en la plaza. Además, el Ayuntamiento tardaría varios años en iniciar mejoras en la plaza. Sin embargo, por las quejas de los vecinos de la plaza y de los adjudicatarios que sí tenían sus negocios en los locales del mercado, es posible inferir que los comerciantes más exitosos eran los ambulantes, revendedores y figoneros que se apiñaban en la plaza del mercado. En ese momento, los comerciantes establecidos exigieron al Ayuntamiento que aplicara la fuerza de la ley para sacarlos de la plaza, pues aquellos no cumplían con sus obligaciones tributarias. Estaban seguros de que usar la fuerza contra los ambulantes no violaba sus derechos, pues eran ellos quienes no cumplían sus obligaciones. ${ }^{19}$ Además podía reubicarlos en un mercado que se estaba construyendo en extramuros; de no tomar una medida, serían ellos quienes abandonarían sus locales.

Como se vio hasta aquí el cobro de los derechos de consumo y mercado respondía a las lógicas en que el mercado había operado cuando el puerto era un lugar de paso. El mecanismo de cobro por el lugar de venta -o sea de mercado-organizaba a los comerciantes clasificándolos como vendedores, revendedores, ambulantes y locatarios. Cuando el comercio regional empezó a recuperarse después de los años de las guerras liberales, las delimitaciones entre

${ }_{18}$ Con esto se referían al pago de derecho de consumo que el gobierno estatal venía tratando de imponer desde 1875, cuando se publicó una larga lista de efectos nacionales provenientes de otros estados que pagarían tal derecho. Este era un impuesto a los "géneros, frutos y efectos nacionales" que se vendieran en el estado, cuyo producto se dividiría en $75 \%$ para el erario del estado y $25 \%$ para el municipal. En principio se estipuló la entrada en vigor de esa ley para el 15 de diciembre de 1875, pero el 9 de ese mes se suspendió indefinidamente. Este derecho, sin embargo, no era nuevo, pues existía y se cobraba por lo menos desde 1873 a distintos establecimientos que vendían productos muy diversos para el consumo local, como mueblerías, estanquillos de licor, cafés, pulquerías, cantinas, casas de empeño, hoteles, tiendas de ropa y camiserías, perfumerías, chocolaterías, expendios de tabaco al menudeo, abarrotes y semillerías con cantina (Colección, 1920, Ley número 173, p. 170).

${ }_{19}$ Archivo Correspondencia. Caja 270, vol. 378, f. 495. Авнмv, México.

\section{()(1) $(3$}


estos comerciantes se hicieron menos claras. Esto porque las posibilidades que se abrieron para entrar al mercado les permitieron crear redes de comercialización que los vincularon de manera distinta. El gobierno entonces buscó controlar esas redes; pero, en el contexto de la reforma liberal, el control tuvo que ser regulado. Las interacciones en el mercado delimitaron los espacios de venta, tanto para los ambulantes como para los establecidos. Estos reacomodos en el centro de la ciudad, donde se unía el mercado urbano con el puerto, afectaron las redes de redistribución de lo que entraba y salía de la ciudad hacia el mercado interno. En el caso de Veracruz, la muralla que había mantenido físicamente separados los ámbitos tributarios de la ciudad y el municipio se rompió antes de que su estructura cayera. Este movimiento abrió nuevas posibilidades para legitimar la reforma fiscal desde el nivel local en el tránsito de los derechos de consumo a los derechos de giro. Para ello hubo toda una reinterpretación de las leyes anteriores a patentes y a la abolición de las alcabalas. Estos cambios en la política fiscal implicaron crear una serie de incentivos para los contribuyentes, lo que permitió mejorar la recaudación.

\section{LA DEFINICIÓN DE LOS ÁMBITOS TRIBUTARIOS DEL AYUNTAMIENTO EN SU INTERACCIÓN CON LOS CONTRIBUYENTES: CONSENSOS DE LA REFORMA FISCAL}

Mientras los comerciantes en la plazuela de San Antonio negociaban la reorganización espacial del mercado, el desarrollo del puerto cambió la distribución comercial más allá del centro de la ciudad. En 1881, el Ayuntamiento realizó el primer padrón de establecimientos en la ciudad que incluyó extramuros, pues un año antes consiguió los permisos para derrumbar la muralla que la rodeaba. Romper esa frontera no sólo significó unir a los porteños, sino expandir el comercio, pues establecimientos como las tiendas de abarrotes o de barrio no pagaban derechos de mercado, los de consumo eran más bajos, vendían al menudeo directamente al cliente y, hasta entonces, los recaudadores no llegaban con facilidad a cobrar en esas áreas.

Por ejemplo, en 1873, el presidente municipal envió una carta al regidor de policía para pedirle que el capitán de gendarmes "exija a los dueños de establecimiento la constancia de haberse inscrito en la Tesorería Municipal [...] según lo dispuesto en el artículo 13 del bando de policía". De acuerdo con el presiente, el desorden en que se encontraba la recaudación de derechos de con-

\section{()(1) $\$$}


sumo salió a la luz cuando, "por un incidente casual [se supo], que un establecimiento de comercio al menudeo situado en extramuros de esta ciudad, no había satisfecho la cuota que debía pagar mensualmente desde que fue el año próximo pasado dispuesto [sic], se obligan a todos las personas que ocurran a hacer la manifestación prevenida en el artículo 73 del reglamento de policía". Por su parte, la Jefatura de Policía respondió que el Ayuntamiento debía comprender "lo difícil que es darles otra tarea" a los gendarmes. No conforme con esta respuesta, el Ayuntamiento explicó al regidor que el problema mayor era que si los dueños de los establecimientos no estaban inscritos en la tesorería, "no se pueda aplicar a los infractores el castigo señalado en el mismo artículo 73", por lo que suplicaba "que por lo menos les deje claro que de no darse de alta incurren en una falta grave y se les acumulan los impuestos". ${ }^{20}$

Otro ejemplo de las dificultades para notificar al comercio y recaudar los derechos municipales en aquella zona es de 1865 , año en que el comerciante Manuel R. Álvarez propuso construir una "casa-mercado" extramuros. Para él, la lógica de la concesión era muy simple: el Ayuntamiento cedería el terreno y el constructor gozaría durante diez años de las rentas generadas por los puestos. Además, Álvarez se comprometía a mantener el edificio en buen estado. El Ayuntamiento no aceptó la propuesta por ser contraproducente para el erario, pues "los vendedores de frutas y otros artículos que vienen del interior [...] podrían eximir el pago de derechos de fortificación y peaje que se cobran a su entrada por la Puerta de la Merced". ${ }^{21}$

Diez años después de la propuesta de Álvarez, "varios vecinos de extramuros" 22 enviaron sus peticiones al Ayuntamiento para establecer un mercado más allá de la muralla. En esa ocasión se aceptó la propuesta y las negociaciones empezaron de inmediato. ${ }^{23}$ Sin embargo, el mercado en el Salón de

${ }^{20}$ Derecho de consumo relativo al presente año. Archivo Correspondencia. Caja 251, vol. 356, fs. 1-4. Авнмv, México,

21 Solicitud de don Manuel R. Álvarez pidiendo se le permita construir por su cuenta en extramuros una casa de mercado, cuya petición fue desechada, 1865. 1880-1881. Archivo Correspondencia. Caja 308, vol. 421, f. 456. Авнмv, México.

${ }^{22}$ Varios vecinos de extramuros piden se establezca un mercado. 1875. Archivo Correspondencia. Caja 268, vol. 376. fs. 576-581. Авнмv, México.

${ }^{23}$ Otros interesados en el negocio de la construcción del mercado en ese edificio fueron los Ritter \& Cía., quienes si bien reconocían la "necesidad de los habitantes", pensaban que el problema más serio eran "los abusos que se cometen diariamente en la compra de carne y pescado a pesar de la mucha vigilancia de la policía”. En los documentos no se aclara si esa compañía estuvo involucrada en la construcción; lo interesante de su participación es que el motivo de la construcción del mercado no sólo era satisfacer la demanda de los habitantes de la zona, sino la necesidad de vigilar la expansión de nuevas formas de comercialización y con-

\section{()(1) $\$$}


Iturbide resultó ser un fracaso, pues después de la radiante inauguración se ocuparon muy pocos locales. ${ }^{24}$ En contraste, en esa área de la ciudad lo que proliferaron fueron las tiendas de abarrotes y las casas de empeño. ${ }^{25}$

Esta distribución espacial del comercio al menudeo refleja que desde 1865 habían ocurrido varios cambios, tanto en las formas de compraventa reguladas por el derecho de consumo, como en los hábitos de compra de la población. Por un lado, las tiendas de abarrotes permitieron a algunos individuos aventurarse a invertir capital en su propio negocio. Por otro lado, el derrumbe de la muralla ayudó a expandir el comercio de mercancías traídas por mar hacia los márgenes de la ciudad para surtir la creciente demanda en los barrios y nuevos asentamientos. Asimismo, propició la dispersión de este tipo de comercios, en los que cada vez había tiendas más pequeñas, con menos capital y de clase más baja. Al menos de eso se quejaban los dueños cuando se les imponía la misma cuota, o una más alta, que a los establecimientos más prósperos.

En este contexto, y con las resistencias ante la reforma tributaria, el Ayuntamiento intentó delimitar qué se vendía en cada establecimiento para reorganizar los mecanismos recaudatorios y, finalmente, sustituir los impuestos indirectos por los directos. La forma de hacerlo fue cambiar los derechos de consumo por los de giro para todo el comercio local. Hasta entonces, los primeros se habían cobrado en Veracruz como parte de un derecho local a la mercancía importada que se comercializaba en la ciudad y, como vimos, concurría con las alcabalas, pero la mercancía nacional no se gravaba. El reto fue entonces normar el consumo de las mercancías nacionales en las ciudades. En los mismos años se emitió la Ley 173 del 22 de septiembre de 1875 para imponer ese derecho a las mercancías nacionales, con base en una lista de cuotas establecidas previamente por producto y no como derecho de con-

trabando en los márgenes de la ciudad. Sobre la construcción de un mercado en extramuros. 1875-1879. Archivo Correspondencia. Caja 277, vol. 386, f. 480. Aвнmv, México.

${ }^{24}$ Plaza del Mercado. 1879. Archivo Correspondencia. Caja 278, vol. 387, f. 557. Aвнмv, México.

${ }^{25}$ A principios de 1880 se expandieron al sur y se concentraron en los alrededores de la Merced y del hospital de Nuestra Señora de Loreto. El otro polo de expansión fue hacia las principales calles de extramuros, donde se registraron 29 tiendas. Cerca del ex convento de la Merced había cinco tiendas (en el ex convento una y la Merced cuatro) y en el hospital de San Sebastián, siete. Esta zona estaba delimitada por la calle Chafalonía y por las calles de la Merced hacia el mar con la Plaza de Santiago y los almacenes de Proveeduría. Los almacenes de Marina o Atarazanas eran tres, de los cuales dos se encontraban prácticamente en ruinas (cerca de la Puerta del Rastrillo). El edificio de Proveeduría lo cedió el gobierno federal al Ayuntamiento en 1856.

\section{()(1) $\$$}


sumo por bulto introducido a la plaza (Colección, 1920, Ley número 173, pp. 124-174). Estos últimos derechos eran recaudados por el jefe político, que era autoridad designada por el gobernador del estado.

Ante las dinámicas en las que el comercio local estaba más fragmentado (en cuanto al capital y tamaño de los establecimientos) y más diversificado (en relación con los productos y efectos que ofrecían los dueños a sus clientes), la nueva legislación buscaba responder a los intentos de control del movimiento mercantil entre el puerto y la ciudad para vigilar el tránsito hacia el mercado interno. En este contexto, y frente a las dificultades administrativas en la aduana marítima para aumentar sus ingresos, el Ayuntamiento tenía que hacer eficiente la recaudación entre los administradores de rentas. Su legitimidad emanaría de la capacidad de levantar un padrón de todo tipo de negocios, tanto de los que se especializaban en bienes de consumo, como de los establecimientos industriales, fondas, cafés y cantinas, tiendas de abarrotes, etc. Con un padrón más completo podía garantizar que todos pagaran impuestos siguiendo un mismo criterio, de acuerdo con una lista en la que se clasificaba la calidad por clase de negocio (primera, segunda, tercera y cuarta), y una serie de cuotas impuestas al establecimiento en función de si vendía bienes de consumo importados o si producía lo que vendía en su mismo establecimiento. Además, cada comercio debía limitarse a un solo giro; de no hacerlo, tendrían que cerrar o simplemente pagar los impuestos diferidos por cada giro que tuviera en un mismo negocio. Sin embargo, lograr un consenso sobre las características de cada establecimiento trajo una serie de conflictos en los que el Ayuntamiento tuvo que negociar con los comerciantes.

En el caso de la clasificación para los establecimientos industriales, los dueños también tuvieron que decidir si vendían en el mismo lugar sus productos, como ropa, camisas, zapatos, escobas, muebles y tabacos. Esto dependía de si los ofrecían al menudeo o al mayoreo y si en el mismo lugar vendían artículos importados. Con los nuevos mecanismos de recaudación, una pregunta obligada era a quién le vendían estos establecimientos industriales y dónde compraban los habitantes de la ciudad al menudeo. Al juzgar por los padrones, la venta de bienes de consumo empezó a aumentar en intramuros, sobre todo en el área que conectaba el centro de la ciudad con la Merced, lo que incluía dulcerías, cantinas, mercerías, tabaquerías, tiendas de ropa, chocolaterías, perfumerías, calzado, panaderías y fondas de alimentos. Estos comercios eran más fáciles de clasificar por producto o giro. Los gravámenes dependían de la producción y el tipo de mercancía (nacional, nacionalizada e importada) y ya no por el lugar de venta y las transacciones de compraventa.

\section{()(1) $(2$}


A partir de las peticiones de los comerciantes al Ayuntamiento es posible analizar la manera en que se definían las formas de comercialización, desde el empeño y otras formas de crédito, hasta el giro del negocio, la calidad y si vendían al mayoreo o al menudeo.

Ante las nuevas dinámicas de comercialización era necesario hacer un reordenamiento espacial del mercado que permitiera controlar el tránsito comercial no sólo en la ciudad, sino en los canales de distribución comercial de la región y hacia la ciudad de México. El Ayuntamiento y el tesorero municipal lo hicieron con base en una clasificación de los establecimientos por tipo de giro, clase y capital invertido. En principio el objetivo de esta transición consistía en evitar la cascada de las alcabalas que debían pagar los productos, desde la salida en su lugar de origen hasta la compra final, y sustituirla por "un solo impuesto, pues así [al contribuyente] se le extorsiona menos, se le ahorra tiempo y trabajo, hay pocos empleados, la contabilidad es más sencilla, el fraude menos fácil y el producto mayor" (Merino, 1998, p. 183). Mientras tanto, en los márgenes de la ciudad los ciclos tradicionales de consumo se rompieron con el aumento poblacional y la aceleración de los ritmos portuarios. Si bien esto no significó que la demanda se mantuviera en el mismo nivel estable todo el año, los dueños de los nuevos establecimientos sí buscaban permanecer todo el año; para ello pedían evitar el incremento de impuestos. Resultó un buen incentivo dejar de pagar los derechos por las transacciones de compraventa y, en su lugar, pagar un impuesto por giro.

Fue entonces cuando el Congreso estatal obtuvo la legitimidad para acceder a los ingresos relacionados con el comercio, sustituyendo los derechos de consumo a los establecimientos comerciales, que gravaban la compraventa, por el de giro de patente. El 3 de julio de 1880 se expidió una ley en la que se estableció que los contribuyentes pagarían $50 \%$ de las cuotas de patente sobre las mercancías extranjeras y bienes importados y comercializados en el estado. Mientras tanto, "[l]os efectos extranjeros ya importados y que proceden de cualquiera puerta o plaza de la república quedan sujetos en los referidos puertos, lo mismo que en cualquiera otro punto del estado al pago de $10 \%$ si se consumiesen en ellos" ${ }^{26}$ Esta disposición legal podía resultar positiva para quienes tuvieran un negocio establecido y se dedicaran a la importación, siempre y cuando no tuvieran que pagar otros derechos de consumo. Por su parte, el cobro de $10 \%$ funcionaba como una protección a los comercios locales que

${ }^{26}$ Decreto de la Legislatura, Orizaba, 3 de julio de 1880 (Colección, 1920, t. 7, p. 57).

\section{()ㅜ(1) $\$$}


vendían mercancía importada por el puerto de Veracruz. Estas leyes modificaron en la práctica las reglas del juego en los mercados urbanos, así como las posibilidades de negociar los mínimos y máximos de giro de patente con las autoridades locales. Al pagar un impuesto directo, no sobre el consumo sino sobre la actividad económica (giro de patente), el costo de la comercialización para los comerciantes locales se redujo, sobre todo para los establecidos.

Este avance hacia una mejor recaudación se vio reflejado en los padrones de establecimientos, en el que los dueños notificaban el giro de su negocio para establecer el monto del gravamen. Para 1889 las notificaciones las enviaron los dueños de los establecimientos directamente al jefe político. ${ }^{27}$ El problema para el Ayuntamiento siguieron siendo los ingresos. Seis años después de la ley del 3 de julio de 1880, el gobernador Juan de la Luz Enríquez reconocía que el cobro de "la cuota del 50\% derecho de patente, no compensa en estos municipios [Veracruz, Córdoba, Xalapa y Orizaba], lo que por derecho de consumo causaban en sus tesorerías municipales los efectos, en el acto de ser introducidos". ${ }^{28}$ Si bien esto seguía siendo un obstáculo, el hecho de que los contribuyentes aceptaran pagar el derecho de giro de patente fue un primer paso para evitar la concurrencia fiscal con la alcabala, pues al mejorar los mecanismos de recaudación, el tesoro del estado tomó la facultad de recaudar los derechos de patente que sustituían a los de consumo. En el cuadro 1 puede observarse el aumento en el ingreso por el derecho de patente.

El éxito se debió a una mejor recaudación como resultado de mecanismos tributarios más eficientes. En términos de la administración tributaria, el gobernador Enríquez llevó a cabo una serie de cambios que le permitieron vigilar más de cerca a los agentes recaudadores locales: desapareció la contaduría de Hacienda, creó la figura de visitador de Hacienda, estableció juntas calificadoras para asignar los derechos de patente en cada caso, definió cuotas mínimas y máximas de los derechos de patente y buscó sustituir los ingresos generados por los derechos de consumo con una mejor recaudación de impuestos directos, por ejemplo, a las fincas urbanas, a la propiedad del establecimiento y de acuerdo con el número de empleados (Blázquez, 1986, t. 5 , p. 2309). Si bien esto último podría haber generado resistencias por parte de los comerciantes, en realidad el acuerdo de pagar derechos de patente en

${ }^{27}$ Notificación de establecimientos comerciales. Archivo Correspondencia. Caja 321, vol. 436, fs. 108-233. Авнмv, México.

${ }^{28}$ Informe del gobernador Juan de la Luz Enríquez (Blázquez, 1986, t. 6, p. 2941).

\section{()(1) $(3$}




\section{Cuadro 1. Recaudación de derecho de patente en Veracruz}

\begin{tabular}{|c|c|c|}
\hline & Autoridad & Derecho \\
\hline Segundo semestre, 1886 & $\begin{array}{l}\text { Ingresos de la Adminis- } \\
\text { tración de Rentas }\end{array}$ & $\begin{array}{l}\text { "Giro de patente", } \\
\text { registrado sólo en los } \\
\text { padrones comerciales } \\
\text { del Ayuntamiento }\end{array}$ \\
\hline 1887 anual & $\begin{array}{l}\text { Oficina de Hacienda: } \\
\text { Administración de } \\
\text { Rentas de Veracruz }\end{array}$ & $\begin{array}{l}\text { Patente } \\
53091.12\end{array}$ \\
\hline Primer semestre, 1888 & $\begin{array}{l}\text { Oficina de Hacienda: } \\
\text { Administración de } \\
\text { Rentas de Veracruz }\end{array}$ & $\begin{array}{l}\text { Patente } \\
\text { Domiciliados } 33967.65 \\
\text { Ambulantes } 468.48\end{array}$ \\
\hline Segundo semestre, 1888 & $\begin{array}{l}\text { Tesoro del estado de } \\
\text { Veracruz }\end{array}$ & $\begin{array}{l}\text { Patente } \\
\text { Domiciliado } 105694.21 \\
\text { Ambulantes } 4749.00\end{array}$ \\
\hline 1889 anual & $\begin{array}{l}\text { Tesoro del estado de } \\
\text { Veracruz }\end{array}$ & $\begin{array}{l}\text { Patente } \\
\text { Domiciliado } 215617.78 \\
\text { Ambulantes } 10193.51\end{array}$ \\
\hline Primer semestre, 1890 & $\begin{array}{l}\text { Tesoro del estado de } \\
\text { Veracruz }\end{array}$ & $\begin{array}{l}\text { Patente } \\
\text { Domiciliado } 114032.07 \\
\text { Ambulantes } 12062.00\end{array}$ \\
\hline
\end{tabular}

Fuente: elaboración propia con base en los datos del movimiento del tesoro del estado (Blázquez, 1986, t. 5, p. 3196).

lugar de los de consumo resultó ser un aliciente para el pago de los impuestos directos. Es decir, gracias al tránsito al derecho de patente fue posible reducir los derechos a la compraventa -recaudados por los regidores de mercados y las autoridades tributarias municipales- que tanto afectaban al comerciante pequeño, porque terminaban por encarecer los precios. El resultado fue que el menor costo del impuesto para el pequeño comerciante establecido le permitió cumplir con otras obligaciones fiscales. Esta lógica tributaria, que recaía en la jurisdicción del Ayuntamiento, demuestra que la negociación de los derechos locales como herramienta política sirvió para legitimar los acuerdos alcanzados a nivel estatal relacionados con la desaparición de las alcabalas.

\section{(ㄷ)(1) $\$$}




\section{CONCLUSIÓN}

Uno de los obstáculos para la reforma fiscal fue la dificultad para establecer un pacto entre las elites regionales y el poder central en un marco federal. Como demostré en este artículo, alcanzar acuerdos para una reforma fiscal que lograra la integración federal requirió que su impulso también viniera desde abajo. En este sentido, en la ciencia política se ha argumentado que las alcabalas fueron aparatos administrativos con la que las autoridades municipales adaptaban una ley muy lejana a la realidad del país, a las prácticas sociales y políticas más arraigadas en la sociedad. Si bien dichas prácticas estaban fuera de la formalidad jurídica, funcionaron ante la inexistencia del estado, sobre todo a nivel municipal. Sin embargo, el análisis del lugar donde se buscaba instrumentar la ley nos da un panorama mucho más complejo de la relación entre la ley y la práctica. El estudio de caso de los acuerdos y desacuerdos para hacer cumplir los reglamentos de mercados en Veracruz muestra cómo la ley se concretó en la interacción entre las autoridades tributarias y los contribuyentes. No ocurrió como una negociación de derechos e impuestos informales en la que las autoridades tributarias ajustaron sus intereses a las prácticas o costumbres ancestrales de los comerciantes; más bien, lo que surgió en ese espacio fue un proceso de interpretación de la ley que permitió formar consensos sobre la legalidad de su aplicación.

Este proceso abrió canales de comunicación política entre los actores comerciales, el Ayuntamiento, el jefe político, el gobierno estatal y las legislaturas locales, lo que implicó rendir cuentas en el ámbito federal. Al integrar en esta historia a los actores que se daban cita en el mercado, las resistencias del Ayuntamiento a transferir las contribuciones federales con base en los derechos locales cobraron otro sentido. Estas resistencias formaron parte de sus estrategias argumentales, a partir de las cuales la institución fue capaz de tomar decisiones legítimas en relación con el tipo de derechos e impuestos que se habrían de recaudar, cómo se habrían de redistribuir hacia la federación, así como la forma en que se ejercería el gasto. Para ello, el Ayuntamiento, como actor urbano con autoridad política en la ciudad, tuvo que superar dos retos: por un lado, las dificultades para establecer prioridades en el gasto como consecuencia de la precariedad de su erario; por el otro, elaborar argumentos que sustentaran su legitimidad como la institución capaz de mediar en los conflictos entre los comerciantes contribuyentes y las autoridades locales y municipales. Esto fue posible gracias a los regidores y los agentes tributarios municipales, quienes exponían las problemáticas que surgían en

\section{(1)(1)}


los mercados en las sesiones de cabildo del Ayuntamiento. Ahí, los miembros del Ayuntamiento deliberaban con base en las quejas y peticiones de los comerciantes y dueños de establecimientos. Los documentos presentados dejan ver cómo los actores retomaban nociones de origen colonial (como prácticas o costumbres antiguas) para adaptar sus demandas al lenguaje liberal del libre comercio y de la "justa competencia", y con ello solucionar conflictos en las nuevas dinámicas de comercialización. En estos conflictos los actores también apelaban al gobierno estatal aprovechando las tensiones a nivel federal. La necesidad de profesionalizar la estructura administrativa, y con ello definir las jurisdicciones de las distintas autoridades que convergían en el puerto, llevó a que el Ayuntamiento cediera parte de su autonomía en relación con la recaudación, gasto y diseño presupuestal. Al mismo tiempo, como órgano de gobierno, logró elaborar argumentos que sustentaran su posición frente a los contribuyentes al transitar de los derechos de consumo a los de giro.

Antes de que se decretara el derecho de patente en 1886, el tesoro municipal empezó a utilizar la clasificación de giro para gravar el comercio en los mercados de Veracruz. El giro se refería simplemente al tipo de negocio de acuerdo con su actividad económica. Esta redefinición de los mecanismos recaudatorios, ante la reforma fiscal, logró evitar que los comerciantes trasladaran el costo de los derechos locales al precio de los productos y mercancías. El pago de dichos derechos se estableció entonces como una contraprestación por el derecho de realizar una actividad económica en un espacio regulado, donde las normas eran claras para todos los comerciantes que participaban en el mercado. De manera que el espacio comercial no sólo era un lugar en la plaza o dentro del edificio del mercado, sino que significaba adquirir derechos y obligaciones legales. A lo largo de este proceso, la legitimidad de la reforma fiscal dependió de la solución de las tensiones entre la ley y la realidad práctica, las cuales surgieron por las dinámicas de comercialización a nivel local. Debido a lo anterior, el Ayuntamiento adquirió una nueva experiencia de gobierno para cambiar las facultades de los representantes de esa institución y sus responsabilidades ante el gobierno estatal.

Las transformaciones in situ, en el diario acontecer del mercado, se complicaron con los lineamientos que empezaban a trazarse en el ámbito federal, tanto en la política comercial como en los acuerdos entre los estados para canalizar la contribución estatal y municipal a la federación. La tensión giró en torno a las razones por las cuales las autoridades locales debían incluir $25 \%$ adicional al cobro de los derechos locales para transferirlo a la contribución estatal, sobre todo mientras no se aclararan los rubros presu-

\section{(이요}


puestales que se asignarían al gasto para la provisión de bienes públicos. El consenso se logró al delimitar las jurisdicciones de las autoridades de los tres niveles de gobierno. En este proceso, la legitimidad del Ayuntamiento en el espacio local radicó en encontrar los mecanismos de recaudación que permitieran no gravar la venta al menudeo por volumen, sino por espacio, para que los comerciantes pudieran expandir su capital. Con ello aminoraron las tensiones con el jefe político, que era el representante del gobierno estatal, pues esta autoridad era la encargada de recaudar los derechos de portazgo y de uso de muelle, que al final eran los derechos directamente relacionados con el tránsito. Así, el Ayuntamiento justificó que los derechos municipales de mercado y consumo eran de su jurisdicción y no debían canalizarse como parte de la contribución federal.

En principio esto significaba que el Ayuntamiento era la autoridad que debía ejercer el gasto en el mantenimiento del mercado. Pero si estos derechos no debían ser considerados como impuestos indirectos -es decir, como gravámenes al comercio- sino al espacio, a la actividad económica que ahí se realizaba y al capital con que contaba el dueño (derecho de giro), entonces la pregunta era si el gravamen sería un impuesto directo. De ser así, debía quedar como parte de la contribución estatal. Esta indefinición se complicó porque primero era necesario acordar los mecanismos fiscales de las contribuciones estatales, es decir, establecer quién tendría la facultad de recaudar y cómo se redistribuirían los ingresos generados en el presupuesto. Este último punto era central para el Ayuntamiento, sobre todo por la necesidad de proveer bienes públicos. Sin embargo, la incertidumbre se mantuvo porque a nivel federal no se llegaba a un acuerdo en cuanto a la eliminación del sistema de alcabalas: la otra fuente más importante de ingresos locales. Uno de los obstáculos a vencer para el estado de Veracruz, como señaló el gobernador Juan de la Luz Enríquez, era defender la soberanía estatal ante la distorsión de precios en los estados colindantes. Como se señaló en este artículo, el gobernador identificó que uno de los principales problemas era el cobro de los derechos de consumo en las ciudades con mayor actividad comercial de la región central.

La solución a este problema dependió de la capacidad de repuesta de las autoridades locales para aplicar los reglamentos en la vida cotidiana y mejorar con ello la recaudación sin afectar al comercio. Regular los establecimientos implicó equilibrar la responsabilidad entre comerciantes, vecinos y autoridades encargadas de la recaudación. En este caso, el gobierno no adquirió ninguna obligación como garante de los servicios públicos -como el mantenimiento

\section{()(1) $(9$}


de los inmuebles, la luz o el agua-, sino que los propietarios -o en su caso los arrendatarios- debían pagar esos servicios como un impuesto aparte de su derecho a vender. Este último fue el impuesto de giro de patente y se gravó con base en la actividad económica, si se trataba de un comercio o una industria productiva y del tipo de mercancía que se vendiera (nacional, nacionalizada o extranjera). Los máximos y mínimos de las cuotas se fijaron en función del capital con que contara el dueño; de la clase de establecimiento, que las autoridades municipales definían de acuerdo con el estado físico del local y de su ubicación; y con base en el giro. La expansión de las pequeñas tiendas, que es algo tradicional en Veracruz, representó un éxito en términos tributarios, pues hacia mediados de 1880 se perfeccionaron los mecanismos recaudatorios para estos establecimientos. Lo anterior responde a que las cuotas definidas en función del capital permitieron a los contribuyentes negociar los máximos y mínimos o, en caso de desacuerdo, no cumplir con las disposiciones fiscales.

Bajo esta presión, el regidor de la tesorería buscó adecuar la ley previa a patentes para evitar que los comerciantes cerraran los negocios o dejaran de pagar. El gravamen que abrió la posibilidad de reinterpretación de esa ley fue el derecho de giro. El contribuyente tuvo que decidir a qué tipo de negocio se dedicaría: compraventa (en la plaza o un comercio establecido); servicios (desde fondas y cafés, hasta hoteles, entre otros); casas de empeño o tiendas de abarrotes; establecimientos de venta de productos locales, o a la producción de manufacturas (ropa, camisas, escobas, cigarros y puros, jabón, joyería, etc.). En cada caso el contribuyente decidía qué le convenía más, si cerrar, pagar, expandir o reducir su capital, o dedicarse a un solo giro para bajar la cuota y mantenerse en la competencia. Si bien esta situación excluyó a algunos actores y redujo la flexibilidad de otros para readaptarse a las tendencias del mercado, el Ayuntamiento tenía la legitimidad de marcar los mecanismos tributarios, pues logró consolidar en ellos un conjunto de ideas y códigos de gobierno. Como institución fue el espacio de organización de la sociedad urbana, al mismo tiempo que dio sentido a la reforma fiscal desde lo local.

\section{LISTA DE REFERENCIAS}

Aboites Aguilar, L. (2001). Alcabalas posporfirianas: modernización tributaria y soberanía estatal. Historia Mexicana 51(2), 363-393.

Blázquez, C. (1986). Estado de Veracruz: informes de sus gobernadores, 1826-1986 (t. 6). Xalapa: Gobierno del Estado de Veracruz.

\section{(ㄷ)(1) $(3$}


Blázquez, C. (2012). Navegación de altura y navegación de cabotaje. Comerciantes veracruzanos y compañías navieras en los tiempos de "paz, orden y progreso", 1880-1900. En F. J. García Aguirre (ed.), Historia económica de Veracruz. Miradas múltiples. México: Universidad Veracruzana.

Carmagnani, M. (1994). Estado y mercado: la economía pública del liberalismo mexicano, 1850-1911. México: FCE/El Colegio de México.

Celaya Nández, Y. (2014). Impuestos locales en la Nueva España: negociación y obra pública en el Ayuntamiento de Veracruz en el siglo XVIII. Espacio, Tiempo y Forma, Serie IV(27), 37-57. DoI: http://dx.doi.org/10.5944/etfiv.27.2014.12708

Colección leyes y decretos de Veracruz, 1824-1919 (1920). Xalapa: Tipografía del Gobierno del Estado.

Estrada y Zenea, I. (1994). La heroica ciudad de Veracruz. Xalapa: Universidad Veracruzana.

Gómez Cruz, F. (2012). Circuitos mercantiles y grupos de poder portuarios. Tuxpan y Tampico en la primera mitad del siglo XIX. Xalapa: Miguel Ángel Porrúa/Universidad Veracruzana.

Gómez Galvarriato, A. y Kourí, E. (2010). La reforma económica. Finanzas públicas, mercados y tierras. En E. Pani (coord.), Nación, Constitución y Reforma, 1821-1908. México: FCE.

Hernández, J. (2006). El mercado urbano de Toluca y su articulación regional 18221854. En M. Miño Grijalva (ed.), Núcleos urbanos mexicanos. Mercados, perfiles sociodemográficos y conflictos de autoridad (pp. 221-272). México: El Colegio de México.

Jáuregui, L. (2003). Vino viejo y odres nuevos. La historia fiscal en México. Historia Mexicana, 52(3), 725-771.

Jiménez, Ch. (2001). Making the city their own: Popular groups and political culture in Morelia, Mexico, 1880 to 1930. (Tesis de doctorado inédita). University of California, San Diego.

Márquez, G. (1998). Tariff protection in Mexico, 1892-1909: Ad valorem tariff rates and sources of variation. En J. Coatsworth y A. M. Taylor (eds.), Latin America and the World Economy since 1800 (pp. 407-442). Cambridge: Harvard Universtiy Press-David Rockefeller Center for Latin American Studies.

Merino, M. (1998). Gobierno local: la contienda por la formación del Estado mexicano. México: El Colegio de México.

Ordóñez López, C. A. (2005). La sucursal del Banco Mercantil de Veracruz en Xalapa, 1904-1910. Veracruz: Instituto Veracruzano de Cultura.

Rhi Sausi, M. J. y Molina A., M. del Á. (2014). El mal necesario. Gobierno y contribuyentes ante el dilema de las alcabalas, siglos XIX y Xx. México: Universidad Autónoma Metropolitana.

\section{()(1) $(3$}


Rodríguez Kuri, A. (1996). La experiencia olvidada. El Ayuntamiento de México: política y gobierno, 1876-1912. México: Universidad Autónoma Metropolitana-Azcapotzalco/El Colegio de México.

Salvatore, R. (2003). Wandering paysanos: State, order and subaltern: Experience in Buenos Aires during the Rosas era. Durham, N. C.: Duke University Press.

Sánchez Santiró, E. (2009). Las alcabalas mexicanas (1827-1857): los dilemas en la construcción de la Hacienda nacional. México: Instituto Mora.

\section{OTRAS FUENTES}

\section{Bibliografía}

Blázquez, C. (1999). Comerciantes, empresarios y banqueros veracruzanos en las postrimerías decimonónicas. En C. Contreras y C. Prado Hernández (eds.), De Veracruz a Puebla. Un itinerario histórico entre la colonia y el porfiriato (pp. 43-56). México: Instituto Mora.

Delgado, A. L. (ed.), Cien viajeros en Veracruz. 11 vols. Xalapa: Gobierno del Estado de Veracruz, 1992.

Lerdo de Tejada, M. (1858). Apuntes históricos de la heroica ciudad de Vera-Cruz (t. III). México: Imprenta de Vicente García Torres.

Márquez, G. (coord.) (2014). Claves de la historia económica de México. El desempeño de largo plazo (siglos XVI-XXI). México: FCE/ConAcultA.

Moreno Toscano, A. (1978). Ciudad de México. Ensayo de construcción de una historia. México: Instituto Nacional de Antropología e Historia (Colección Científica).

Sabato, H. y Romero, L. A. (1992). Los trabajadores en Buenos Aires: la experiencia del mercado, 1850-1880. Buenos Aires: Sudamericana.

Trejo Bajaras, D. (1999). Espacio y economía en la península de California, 1785-1860. La Paz: Universidad Autónoma de Baja California. 